\title{
BMJ Open The disciplined healthcare professional: a qualitative interview study on the impact of the disciplinary process and imposed measures in the Netherlands
}

\author{
Lise M Verhoef, ${ }^{1}$ Jan-Willem Weenink, ${ }^{1}$ Sjenny Winters, ${ }^{1}$ Paul B M Robben,,${ }^{2,3}$ \\ Gert P Westert, ${ }^{1}$ Rudolf B Kool ${ }^{1}$
}

To cite: Verhoef LM, Weenink J-W, Winters S, et al. The disciplined healthcare professional: a qualitative interview study on the impact of the disciplinary process and imposed measures in the Netherlands. BMJ Open 2015;5: 0009275 . doi:10.1136/bmjopen-2015009275

- Prepublication history for this paper is available online. To view these files please visit the journal online (http://dx.doi.org/10.1136/ bmjopen-2015-009275).

Received 30 June 2015 Revised 2 November 2015 Accepted 3 November 2015

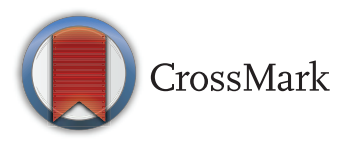

\footnotetext{
${ }^{1}$ Scientific Institute for Quality of Health Care, Radboud Institute for Health Sciences, Radboud University Medical Centre, Nijmegen,

The Netherlands

${ }^{2}$ Institute of Health Policy \&

Management, Erasmus

University, Rotterdam,

The Netherlands

${ }^{3}$ Department of Research and Innovation, Health Care Inspectorate, Utrecht, The Netherlands
}

Correspondence to Lise M Verhoef; liseverhoef@gmail.com

\section{ABSTRACT}

Objective: It is known that doctors who receive complaints may have feelings of anger, guilt, shame and depression, both in the short and in the long term. This might lead to functional impairment. Less is known about the impact of the disciplinary process and imposed measures. Previous studies of disciplinary proceedings have mainly focused on identifying characteristics of disciplined doctors and on sentencing policies. Therefore, the aim of this study is to explore what impact the disciplinary process and imposed measures have on healthcare professionals.

Design: Semistructured interview study, with purposive sampling and inductive qualitative content analysis.

Participants: 16 healthcare professionals (9 medical specialists, 3 general practitioners, 2 physiotherapists and 2 psychologists) that were sanctioned by the disciplinary tribunal.

Setting: The Netherlands.

Results: Professionals described feelings of misery and insecurity both during the process as in its aftermath. Furthermore, they reported to fear receiving new complaints and provide care more cautiously after the imposed measure. Factors that may enhance

psychological and professional impact are the publication of measures online and in newspapers, media coverage, the feeling of treated as guilty before any verdict has been reached, and the long duration of the process.

Conclusions: This study shows that the disciplinary process and imposed measures can have a profound psychological and professional impact on healthcare professionals. Although a disciplinary measure is meant to have a corrective effect, our results suggest that the impact that is experienced by professionals might hamper optimal rehabilitation afterwards. Therefore, organising emotional support should be considered during the disciplinary process and in the period after the verdict.

\section{BACKGROUND}

In the past decades, patient safety has gained considerable attention and the importance of addressing medical incidents has been

\section{Strengths and limitations of this study}

- We performed interviews with healthcare providers from a range of professions with a mix of cases and imposed measures.

- A good response rate was achieved, considering the sensitive topic.

- The study population might be subjected to selection bias.

increasingly recognised. ${ }^{1}{ }^{2}$ Incidents often relate to system-level or organisational aspects of healthcare. ${ }^{3}$ Some are, however, attributable to individual healthcare professionals. ${ }^{4}$ In these cases, disciplinary proceedings may be initiated to address the healthcare professional. Countries differ in their system of disciplinary proceedings. In the Netherlands, disciplinary law is embedded in the Healthcare Professionals Act and applies to eight regulated healthcare professions: dentists, midwives, nurses, pharmacists, physicians, physiotherapists, psychologists and psychotherapists. ${ }^{5}$ The goal of disciplinary law is first corrective to repress incompetent and careless behaviour of healthcare professionals and second normative to clarify the professional standard. It should improve the quality of healthcare and enhance public trust in the medical profession. ${ }^{6}{ }^{7}$ In Dutch disciplinary law, patients do not receive financial compensation if the healthcare professional is found to be at fault, such as is the case in a malpractice system. ${ }^{8}$

To achieve its goals, the Dutch disciplinary tribunal can impose a number of measures. Healthcare professionals can be disciplined with a warning, a reprimand, a monetary fine, a (conditional) suspension, deprivation of the right to perform certain procedures or of the right to re-registration (in case a professional voluntarily unregisters), or 
removal from the register. ${ }^{5}$ For the latter, the professional loses the right to carry out the profession. For all other measures, however, the professional is expected to proceed with or return to (a subset of) his or her activities.

It is known that doctors who receive complaints may have feelings of anger, guilt, shame and depression, both in the short and in the long term. ${ }^{9}{ }^{10}$ In case of medical errors, healthcare professionals are often impacted as 'second victims', experiencing similar feelings as patients and family. ${ }^{11}$ This may lead to functional impairment. ${ }^{11}{ }^{12}$ Less is known about the impact of the disciplinary process and imposed measures. Previous studies of disciplinary proceedings have mainly focused on identifying characteristics of disciplined professionals and on sentencing policies. ${ }^{13-16} \mathrm{~A}$ recent report on suicides of doctors while under investigation of the General Medical Council (GMC) suggested that the impact of investigation on individual doctors and how sanctions affect a doctor's career should be audited. ${ }^{17}{ }^{18}$ The aim of this study was to examine what impact the disciplinary process and imposed disciplinary measures can have on healthcare professionals.

\section{METHODS}

To answer our research question, we have chosen to perform semistructured interviews since this is an appropriate method to explore people's experiences and attitudes. ${ }^{19}$ We chose to use individual interviews because of the sensitivity of the topic and because of the diversity of cases. A semistructured interview guide was used to explore predefined topics but also to be able to anticipate on the professionals' experiences. We interviewed 16 healthcare professionals that were confronted with a disciplinary measure. To select these professionals, we used a list of all healthcare professionals on whom disciplinary measures have been imposed. Since July 2012, this list is publicly available on the website of the organisation that regulates the Dutch licences. It includes all imposed measures (except warnings and monetary fines) on healthcare professionals of the eight legally registered professions (https://www.bigregister.nl/). We used data from 1 July 2012 until 28 March 2014.

\section{Participant selection}

In total, 211 professionals were listed in the file. After exclusion of individuals with a 'last known address' abroad, 183 professionals were eligible for inclusion. These concerned 87 physicians, 31 nurses, 21 dentists, 16 healthcare psychologists, 13 psychotherapists, 11 physiotherapists and 3 midwives. No pharmacists were present on the list. Since the different professions were unequally represented, we aimed to include a proportional mix of healthcare professionals with a minimum of one per profession by purposive sampling. When no one within a profession was eligible for the study or willing to participate, we tried to include more professionals from other professions. Professionals were excluded if the specific events that led to the imposed measure took place abroad, or if the contact details of the professional could not be apprehended.

Thirty-four healthcare professionals were invited for an interview by letter in which a clear description of the study and an outline of the interview were provided. Also, the process of member check and anonymity were described. Professionals that did not respond were phoned up to five times as a reminder. Sixteen professionals indicated they were willing to participate in the study, whereas 12 did not want to cooperate and 6 did not respond. Main reasons for not participating were that the professional wanted to leave the past behind or did not want to recall the specific events.

\section{Interviews}

In order to answer the research questions, an inventory of possible themes to explore with the interviewees was made based on the current literature and a brainstorm with three researchers (LMV, SW and RBK). Based on this inventory, two researchers (LMV and SW) developed a semistructured interview guide. The third researcher (RBK) commented on this. After two interviews, the interview guide was adapted on some details. The guide focused on (1) a reflection of the events that led to the disciplinary process and on (2) professionals' experiences with and the impact of the disciplinary process and imposed measures. This paper focuses on the latter, and does not include specific information of each case. This was done to ensure anonymity of the participants and because there was great variation in the events that led to the measure and the ability of the interviewees to reflect on these events. One researcher performed the interviews (LMV). Interviews were held face-to-face, without anyone else present, at a location chosen by the professional unless he/she preferred a telephone interview $(n=5)$. The interviewer was female and had experience and training in performing interviews. No relationship was established with interviewees prior to the study. Field notes were made during the interview. All interviews were recorded and transcribed verbatim. Interviewees gave permission to use the anonymous interview report for analysis.

\section{Analysis}

In this study, we used inductive qualitative content analysis in which we explored themes and categories that emerged from the data. This analysis was done using Atlas-ti V.7.1. A codebook was developed based on this inductive analysis. ${ }^{20}$ Two researchers (LMV and J-WW) first analysed three interviews separately. They discussed differences until consensus was reached, and if necessary, the codebook was adapted. Remaining interviews were coded by one of the two researchers, and checked by the other researcher. Discrepancies were discussed until consensus was reached. Results, progress and data saturation were discussed during the process. 


\section{Setting}

In the Netherlands, there are five disciplinary law tribunals. Any person who has been in the care of a healthcare professional (either as a patient or as a patient's relative) can file a complaint. Next to this, the Dutch healthcare inspectorate can file complaints. The healthcare inspectorate is responsible for approximately $2 \%$ of the complaints. ${ }^{6}$ Complaints can be submitted until 10 years after the events. When the tribunal receives a complaint, it first assesses the nature of the complaint. If the complaint is found to be inadmissible, it is rejected. When the complaint is accepted, a public hearing takes place. The complainant and defendant are not obliged to be present at the hearing, however, in court both parties get the opportunity to clarify their views and answer the questions of the tribunal. After this, the tribunal will deliberate and make a decision. After a tribunal verdict, it is possible for the complainant and the defendant to file a high appeal at the central disciplinary tribunal. The complete process takes approximately 9 months on average, with a high appeal taking an extra year on average. In 1995, 792 complaints were filed. In 2013, this number was more than doubled to 1640 complaints, of which approximately two-third concern physicians. In $2013,15 \%$ of the handled complaints resulted in a conviction of the healthcare professional. ${ }^{21}$

\section{RESULTS}

\section{Study population}

After 16 interviews, few new codes and no new overarching themes emerged from the data. Therefore, we decided to stop further recruitment of participants. The 16 participating professionals included 12 physicians (9 medical specialists, 3 general practitioners), 2 physiotherapists and 2 healthcare psychologists. Four of them were working in a solo practice, six with colleagues in a group practice and six were employed in an organisation. Thirteen professionals were men and three women. The imposed measures included 12 reprimands, 1 suspension and 3 removals from the register. Reasons for these measures included the provision of substandard care, incorrect diagnosis, inappropriate behaviour towards patients, and breach of confidentiality. All verdicts took place more than 6 months before the interview and most cases were concluded not longer than 2 years prior to our study.

On average, interviews lasted $1 \mathrm{~h}$. There was great variety in the way the professionals reflected on the events. Some healthcare providers blamed everything that had happened on themselves. Other interviewees (partly) disagreed with the complaint and/or imposed measure. Several professionals felt that they were treated unfairly or questioned the methods, expertise and judgement of the disciplinary board.

\section{Psychological impact}

The analysis of the interviews showed that a disciplinary measure and the process around it can have a huge impact on healthcare professionals. On a personal level, the period may leave a deep impression, although some professionals indicated that the impact of the process on their emotional well-being was limited. Several professionals indicated that they felt insecure, powerless and sometimes even depressed during the disciplinary process. Also, the treatment during the hearing of the disciplinary board was a negative experience for several interviewees. For example, one professional felt to be treated as guilty during the disciplinary process. These negative feelings were not limited to the disciplinary process, but for some endured long after the process had come to an end, with some experiencing sleepless nights and reliving the disciplinary process for a year after it concluded. Some professionals indicated to have sought counselling or psychological help after the disciplinary process. Furthermore, some professionals felt threatened by the patient and their family during the process. Several professionals were afraid for new complaints after the process had ended. Some stated that their colleagues experienced these feelings as well. Box 1 presents an overview of quotes from the interviews, related to psychological impact.

\section{Professional impact}

The disciplinary process takes time and may require a lot of energy. One professional indicated to have stopped working for a few weeks to prepare for the disciplinary process, and to avoid being distracted in providing patient care.

\section{Box 1 Psychological impact}

\section{Misery}

"It's a very negative experience and it's annoying for the family as well. It gets you down and almost makes you depressed, although you get over it as well."

"I had the impression that I had to pay [for my mistake]. It's the impression I had from the moment I walked in [the disciplinary hearing], just by the way they treated me."

Fear

"I was afraid afterwards (after the disciplinary hearing), because I had to walk outside and didn't have the police guarding me. I was thinking about what that man (the complainant) would do. He was delusional and had developed paranoid delusions about his treatment. What was he going to do at the moment I walked outside alone?"

"I'm terribly afraid of white envelopes because the disciplinary boards' letters are in a big A4 envelope that only has a postal code on it."

\section{Long-term impact}

"I don't relive being in front of the disciplinary board anymore. For about a year I would wake up every night at $3 \mathrm{AM}$ and would start to explain what had happened."

Interviewer: "Did you receive any support or assistance in the period after you were suspended, or would you have required any?"

Professional: "No. I certainly needed it, but I arranged it myself. I needed counselling." 
Some interviewees experienced support from their organisation, for example, from their direct colleagues, though one professional indicated that the process damaged his trust in colleagues and that it was harder to get things done in the organisation after the measure.

Professionals described several ways of dealing with the imposed measure. Some found a way to work around the constraints, for example, by working as a medical consultant or by transferring some activities to registered professionals.

In response to the imposed measure, several professionals said they became overcautious because they wanted to prevent complaints and did not want to experience the disciplinary process again. Some even stated that they avoided treating certain patients or cases.

The disciplinary process and measure also had financial impact on the disciplined professionals. The disciplinary process itself can lead to high costs for the professional, for example, hiring a lawyer. Some healthcare professionals indicated that they lost patients due to the imposed measure, though others indicated that, despite the measure, patients kept coming to their practice. One interviewee experienced that competing professionals from the same profession used the measure as an argument to keep patients away from him. Discontinuing working as a healthcare professional, for example, due to a suspension, has financial consequences as well due to a loss of income. Box 2 presents an overview of quotes from the interviews, related to professional impact.

\section{Factors enhancing psychological and professional impact}

A recurring theme in the interviews is the overt publication of disciplinary measures. None of the professionals was positive about this policy. Especially the fact that verdicts are sometimes published in local newspapers is found to be unnecessary and harmful. Some professionals stated that patients cannot fully understand the considerations and decision-making behind a certain verdict and might wrongly decide to avoid the healthcare professional. Also, other media might copy the published information, which could impact the healthcare professional profoundly. For example, searching with Google might only result in information about the imposed measure. This does not only impact the healthcare professional, but also his family and colleagues as mentioned by some professionals. Furthermore, information on the internet might be present until long after the measure has expired (a reprimand, eg, expires after 5 years). Several interviewed professionals felt unfairly labelled as criminals while it was never their intention to do anything wrong. They thought that the media played a major role in this 'condemnation' of healthcare professionals. In their opinion, journalists are not looking for the truth but want to write juicy stories. One interviewee suggested that disciplinary law should reduce sentences in cases that receive a lot of media attention,

\section{Box 2 Professional impact}

\section{Interference with patient care}

Professional: "We took one or two weeks leave from work at the start of the disciplinary case, so we could prepare in peace. It's not good if you're thinking about these things."

Interviewer: "While you're working..."

Professional: "You just can't take care of people [while preparing for the disciplinary hearing], so that's what we did. But you can't continue taking leave forever so, eventually, we returned to work. And then it takes about half a year before the disciplinary hearing takes place. That is a very long time for the people involved."

\section{Colleagues and organisation}

"Look, I spoke to someone who had experienced the same thing, a psychiatrist. And that's wonderful because you both have that same powerless feeling; that feeling that you try so hard, work so hard and make an effort, and then you get this for some nonsense. That is encouraging."

"Well, I have zero trust in my colleagues. If we experience another situation that I expect might go the same way, then l'll be the first to knock on the door of journalists to give my own explanation to a media organisation of my choice, rather than giving information to people who only want a sensational front page."

\section{Defensive practice}

"Yes, I'm constantly hedging."

"But I did become afraid. I used to be carefree in my practice but that has been affected, and for that I blame the system."

"Well, initially you start to distrust people. You begin to wonder whether each of your patients could be a potential complainant. That's the response you have."

\section{Financial consequences}

"It has cost me a lot of money to go to the disciplinary board with a lawyer."

"The impact is, in the way I experience it, that I get clients that are referred to me or received a recommendation for me. And after they've visited me, they search the internet, and then immediately cancel their treatment."

which is common in criminal law. Also, some interviewed professionals stated it is hard for care providers to defend themselves against claims by patients in media because they are bound to the law of confidentiality.

Several interviewees stated that the disciplinary process takes too much time, which contributes to feelings of stress. Some professionals decided not to file an appeal because they did not want to go through the whole process again, even though they did not agree with the outcome of the disciplinary process. Box 3 presents an overview of quotes from the interviews, related to factors enhancing psychological and professional impact.

\section{DISCUSSION}

\section{Principal findings}

This study shows that the disciplinary process and imposed measures can have a profound impact on healthcare professionals. Professionals described feelings of misery and insecurity both during the process as in its aftermath. Furthermore, they reported to fear receiving 
Box 3 Factors enhancing psychological and professional impact

\section{Publication of measures}

"The reprimand comes with an ad in the newspaper. I can only say, that's just abusive. Your surname, given name, profession and place of residence are all listed in the newspaper after you've made a wrong diagnosis. I mean how many people with that name live in the same city. A criminal is only listed with his initials, and they have done something wrong on purpose."

"Imagine that your daughter comes to you and says: 'Dad, what's this thing I read about you on the internet?'”

"Publishing the measure with both given name and surname is unnecessarily hurtful, and it creates a lot of anxiety among patients. It gives patients the feeling of being unsafe. Patients can't assess the grounds for such a verdict."

Media coverage

"One of my colleagues spoke to the press. When you see the part that was aired on television, the part that they took from it, you see him saying three things, but they've excluded everything else he explained. So it sounds as everything went completely wrong."

"Patients can say whatever they want in the media, but a doctor can't defend himself because when he does say something, he violates the law of confidentiality."

Duration of the disciplinary process

"It's terrible, and it goes on and on. The complete process lasted four years."

"I didn't agree with it [the disciplinary verdict] completely, but thought it won't help anyone going through all of this again."

new complaints and provide care more cautiously after the imposed measure, sometimes leading to defensive practice. Factors that may enhance the psychological and professional impact are the duration of the disciplinary process and time, money and energy this takes, as well as the overt publication of measures and possible media coverage the case receives. Although a disciplinary measure is meant to have a corrective effect, our results suggest that the impact that is experienced by professionals might also hamper optimal rehabilitation. However, our results do not indicate that all healthcare professionals under investigation have similar experiences. The impact of disciplinary procedures differs among professionals, and may depend on context, severity of the case, and individual characteristics of the professional.

\section{Strengths and limitations}

Our study included a range of healthcare professions with a mix of cases and imposed measures, and had a relatively good response rate considering the sensitive subject and the varying group of interviewees. It has, however, some limitations. The results may be influenced by our selection. First, our study only included professionals that were sanctioned. This is a minority (approximately 15\%) of all professionals against whom a complaint is filed at the disciplinary tribunal. ${ }^{21}$ Their experiences might differ from those of professionals that were not sanctioned. Professionals that were sanctioned might look back with a more negative recollection of how things went down and how they felt. Second, our study population was not in all aspects representative for the group healthcare professionals with an imposed measure especially because it lacked dentists and nurses. Those two groups together comprehended a quarter of all substantive complaints in $2013 .^{21}$ Concerning the type of imposed measure our sample did seem to be representative with a slight over-representation of reprimands and removals from the register. ${ }^{21}$ Finally, the number of interviewees was limited, which might restrict the generalisability.

It is known that the background and preconceptions of the researchers influence the findings and conclusions, especially in qualitative research. ${ }^{22}$ To strengthen the design of our study both researchers experienced with the research theme as researchers relatively new to the subject were involved in study design and analysis. A researcher new to the subject but experienced in qualitative healthcare research collected the data.

\section{Comparison with other research}

The major psychological impact shown in our results confirms the results of a recent study into the emotional responses of physicians to complaints. This study showed an association between complaints procedures and risks on depression, anxiety and suicidal ideation. ${ }^{23}$ Another study revealed that anger, distress and the feeling to be personally attacked are common responses to litigation. ${ }^{24}$ Professionals in our study emphasised similar responses to the disciplinary process. This psychological impact might also be reflected by the main reasons for non-respondents not to participate. They wanted to leave it all behind them, and did not want to recall the specific events. The length of the disciplinary process was often mentioned as a factor that contributed to the emotional impact. Professionals experienced the duration of the process, which on average takes approximately 9 months (with a high appeal adding an extra year on average), as too long and as a source of inducing stress. ${ }^{21}$ For some professionals, it was the sole reason for not filing an appeal, since they did not want to go through the process again and experience the same feelings. Furthermore, some professionals mentioned that they felt they were treated as already found guilty during the process, resulting in feelings of powerlessness. This notion is also recognised in the evaluation report of the GMC, in which it was recommended to establish a culture where doctors feel they are treated as 'innocent until proven guilty'. ${ }^{25}$

The professional impact by changing behaviour out of fear for new complaints and therefore being overcautious has been identified by previous studies as an adverse outcome of the complaints process. ${ }^{26} 27$ This can be positive, for example, overdocumentation and consenting, or negative, that is, withdrawal from the doctor-patient relationship. A recent study among 
physicians in the UK showed that $89 \%$ with a recent and $83 \%$ with a past complaint reported hedging behaviour as a result of the complaint; $50 \%$ of doctors with a current and $43 \%$ of doctors with a past complaint reported avoidance behaviour. ${ }^{23}$ The disciplinary process might also interfere with providing care as a result of the time and energy it takes and its associated costs. Professionals going through a complaints process often take time off work. ${ }^{23}$ Furthermore, interprofessional relations and the professionals' position within the organisation might be influenced, with professionals going through the complaints process previously having reported that they felt bullied. ${ }^{23}$

Since July 2012 the imposed measures (except monetary fines and warnings) are published online in the Netherlands with name, profession, place of residence and a short description. Most verdicts are published anonymously on the website of the disciplinary boards. Verdicts that are found to be informative for a larger audience can be published anonymously in the government gazette or a medical journal. Furthermore, all measures (except warnings) are published in a local newspaper, mentioning name, profession and place of residence. ${ }^{28}$ This publicity policy has been highly criticised by respondents, and was experienced as unnecessary and harmful. In the UK, the Medical Defence Unit recently pleaded that the GMC should scrap the warnings, a low level GMC sanction, because it might negatively affect doctor's career because employers might mistake them for something more serious. ${ }^{29}$ Professionals in our study mentioned these consequences as well, furthermore making note of the fact that patients possibly are not capable to distinguish between types of measures. In the Netherlands, the medical association pleaded in 2013 to scrap publication of reprimands and monetary fines. ${ }^{30}$

Additional media coverage on the case might enhance emotional impact. Especially coverage on the case before a verdict has been reached can increase the feeling of treated as guilty. Some respondents felt like they were labelled as a criminal. Online media coverage might impact the disciplined healthcare professional for long after the process, with the case coming up every time their name is typed in a search engine. Recently the opportunity arose to ask search engines to delete certain links to webpages that might be harmful and lay in the past, the so-called 'right to be forgotten'. ${ }^{31}$ This, however, does not erase the specific webpage (only the links), and people might still be able to retrieve the information using other strategies. Respondents mentioned that public measures and additional media coverage furthermore contribute to the social impact the process has, with people in their near environment asking them about the situation.

\section{Implications and further research}

Because of the huge psychological impact and the possible consequences for rehabilitation afterwards, our findings suggest a need for moral support of professionals before, during and after the disciplinary process. This kind of support is currently absent in the Netherlands, as well as in most other countries. In the UK, however, any doctor who is being investigated by the GMC can access the GMC's Doctor Support Service provided by the BMA Doctors for Doctors Unit. This service provides free confidential emotional support from a specialty trained fellow doctor accompanying a doctor to a hearing if their case has been referred to a Medical Practitioner Tribunal Service (MPTS) panel. ${ }^{32}$ Also, in New Zealand, a funded counselling service for stressed doctors was found to be effective and well received. ${ }^{33}$ Further research is needed to examine if and how this emotional support should be organised in the Netherlands. Furthermore, disciplinary tribunals should take into account the stress and emotional impact that healthcare professionals experience, and assess if it is deemed necessary to adjust their procedures and communication accordingly. Our findings suggest that there are several factors that impact professionals in executing their profession after the imposed measure. These concern intrinsic factors of the healthcare professional, such as distress and the fear of new complaints, as well extrinsic factors in his environment such as the relation with other healthcare professionals. High rates of recidivism have been identified for physicians that are sanctioned. ${ }^{34}$ Finding a way of dealing with these factors is therefore of great importance for adequate rehabilitation of the disciplined professional. Further research is needed to identify adequate ways to address these factors, and examine what responsibility organisations, professional bodies and other relevant authorities should take.

\section{Twitter Follow Rudolf Kool at @tijnkool}

Contributors LMV performed the interviews; LMV, J-WW, SW and RBK were involved in analysis and interpretation of the data; LMV and J-WW drafted the manuscript; all authors contributed to the design of the study and critically revised the manuscript. LMV and RBK are guarantors of this study.

Funding This study was performed in the context of a project funded by ZonMw, the Netherlands Organisation for Health Research and Development. Project number 516001002 . The publication fee was reimbursed by the Netherlands Organisation for Scientific Research (NWO).

\section{Competing interests None declared}

Provenance and peer review Not commissioned; externally peer reviewed.

Data sharing statement No additional data are available.

Open Access This is an Open Access article distributed in accordance with the Creative Commons Attribution Non Commercial (CC BY-NC 4.0) license, which permits others to distribute, remix, adapt, build upon this work noncommercially, and license their derivative works on different terms, provided the original work is properly cited and the use is non-commercial. See: http:// creativecommons.org/licenses/by-nc/4.0/

\section{REFERENCES}

1. Kohn LT, Corrigan JM, Donaldson MS, eds. To err is human: building a safer health system. The National Academies Press Washington DC, 2000. 
2. Stelfox HT, Palmisani S, Scurlock C, et al. The "To Err is Human" report and the patient safety literature. Qual Saf Health Care 2006;15:174-8.

3. Jones A, Kelly D. Deafening silence? Time to reconsider whether organisations are silent or deaf when things go wrong. BMJ Qual Saf 2014;23:709-13.

4. Leape LL, Fromson JA. Problem doctors: is there a system-level solution? Ann Intern Med 2006;144:107-15.

5. Hout FA, Cuperus-Bosmat JM, de Peuter OR, et al. [Disciplinary measures for healthcare practitioners in the Netherlands 19832002]. Ned Tijdschr Geneeskd 2007;151:881-6.

6. Hout FAG, Kaupmann NL, Alhafaji FY, et al. Tuchtklachten van de Inspectie voor de Gezondheidszorg effectief voor aangeklaagden en beroepsgenoten. Tijdschr Gezondheidswetenschappen 2011;89:58-64

7. Sijmons JG, Woestenburg NOM, Dorscheidt JHHM, et al. Tweede evaluatie Wet op de beroepen in de individuele gezondheidszorg. [Second evaluation of the Healthcare Professionals Act]. ZonMw Den Haag October 2013 (in Dutch).

8. Gaal S, Hartman C, Giesen P, et al. Complaints against family physicians submitted to disciplinary tribunals in the Netherlands: lessons for patient safety. Ann Fam Med 2011;9:522-7.

9. Cunningham $W$. The immediate and long-term impact on New Zealand doctors who receive patient complaints. $N Z$ Med J 2004;117:U972.

10. Cunningham W, Wilson $\mathrm{H}$. Complaints, shame and defensive medicine. BMJ Qual Saf 2011;20:449-52.

11. Scott SD, Hirschinger LE, Cox KR, et al. The natural history of recovery for the healthcare provider "second victim" after adverse patient events. Qual Saf Health Care 2009;18:325-30.

12. Waterman $A D$, Garbutt J, Hazel E, et al. The emotional impact of medical errors on practicing physicians in the United States and Canada. Jt Comm J Qual Patient Saf 2007;33:467-76.

13. Alam A, Klemensberg J, Griesman J, et al. The characteristics of physicians disciplined by professional colleges in Canada. Open Med 2011;5:e166-72.

14. Khaliq AA, Dimassi $\mathrm{H}$, Huang $\mathrm{CY}$, et al. Disciplinary action against physicians: who is likely to get disciplined? Am J Med 2005;118:773-7.

15. Morrison J, Wickersham P. Physicians disciplined by a state medical board. JAMA 1998;279:1889-93.

16. Oomen RJ, Biesaart MC. [Removal from the Dutch healthcare professionals register: considerations taken into account by the disciplinary tribunal from 2006 to 2011]. Ned Tijdschr Geneeskd 2012;156:A5269.

17. Moberly T. GMC should audit effects of its investigations on doctors, report recommends. BMJ Careers 2015. http://careers.bmj.com/ careers/advice/GMC_should_audit_effects_of_its_investigations on_doctors,_report_recommends (accessed Nov 2015).
18. Rimmer A. Report on suicides of doctors under GMC investigation will trigger review of procedures. BMJ Careers 2014. http://careers. bmj.com/careers/advice/view-article.html?id=20020063 (accessed Nov 2015).

19. Pope C, van Royen P, Baker R. Qualitative methods in research on healthcare quality. Qual Saf Health Care 2002;11:148-52.

20. Pope C, Ziebland S, Mays N. Qualitative research in health care. Analysing qualitative data. BMJ 2000;320:114-6.

21. Jaarverslag 2013 [Annual report 2013]. Tuchtcolleges voor de Gezondheidszorg en College van Medisch Toezicht March 2014 (in Dutch).

22. Malterud K. Qualitative research: standards, challenges, and guidelines. Lancet 2001;358:483-8.

23. Bourne T, Wynants L, Peters $M$, et al. The impact of complaints procedures on the welfare, health and clinical practise of 7926 doctors in the UK: a cross-sectional survey. BMJ Open 2015;5:e006687.

24. Bark $P$, Vincent $C$, Olivieri $L$, et al. Impact of litigation on senio clinicians: implications for risk management. Qual Health Care 1997;6:7-13.

25. Horsfall S. Doctors who commit suicide while under GMC fitness to practise investigation. General Medical Council, 2014.

26. Cunningham W, Dovey S. Defensive changes in medical practice and the complaints process: a qualitative study of New Zealand doctors. N Z Med J 2006;119:U2283.

27. Nash LM, Walton MM, Daly MG, et al. Perceived practice change in Australian doctors as a result of medicolegal concerns. Med J Aust 2010;193:579-83.

28. Smit M. Ook berisping zorgverlener in lokale krant. Medisch Contact, 2013. http://medischcontact.artsennet.nl/archief-6/Tijdschriftartikel/ 128170/Ook-berisping-zorgverlener-in-lokale-krant.htm

29. Rimmer A. GMC warnings should be scrapped, says MDU. BMJ Careers 2014. http://careers.bmj.com/careers/advice/view-article. html?id=20020085 (accessed Nov 2015).

30. Artsen willen stop op openbare berispingen. Skipr 2013. http://www. skipr.nl/actueel/id14046-artsen-willen-stop-op-openbare-berispingen. html (accessed Nov 2015)

31. Payne D. Google, doctors, and the "right to be forgotten". BMJ 2015;350:h27.

32. GMC to review its treatment of vulnerable doctors under fitness to practise investigation GMC. 2014. http://www.gmc-uk.org/news/ 26011.asp

33. Cunningham W, Cookson T. Addressing stress-related impairment in doctors. A survey of providers' and doctors' experience of a funded counselling service in New Zealand. N Z Med J 2009;122:19-28.

34. Grant D, Alfred KC. Sanctions and recidivism: an evaluation of physician discipline by state medical boards. $J$ Health Polit Policy Law 2007;32:867-85. 